\title{
Cytoreductive radiotherapy combined with abiraterone in metastatic castration-resistance prostate cancer: a single center experience
}

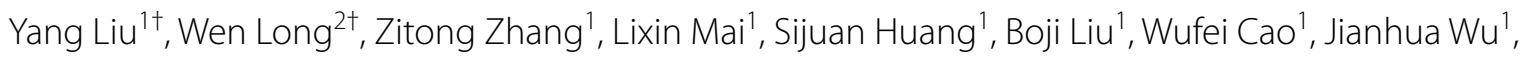
Fangjian Zhou ${ }^{3}$, Yonghong $\mathrm{Li}^{3^{*}}$ and Liru He ${ }^{1^{*}}$ (1)

\begin{abstract}
Background: To investigate the potential benefit of cytoreductive radiotherapy (cRT) in metastatic castration-resistant prostate cancer ( $\mathrm{mCRPC}$ ) patients receiving abiraterone.

Methods: From February 2014 to February 2019, 149 mCRPC patients treated with abiraterone were identified. Patients receiving CRT before abiraterone failure (AbiRT group) were matched by one-to-two propensity score to patients without CRT before abiraterone failure (non-AbiRT group).

Results: The median follow-up was 23.5 months. Thirty patients (20.1\%) were in the AbiRT group, whereas 119 patients (79.9\%) were in the non-AbiRT group. The 2-year OS of patients managed by AbiRT and non-AbiRT were $89.5 \%$ and $73.5 \%$, respectively $(P=0.0003)$. On multivariate analysis, only AbiRT (HR $0.17 ; 95 \% \mathrm{Cl} 0.05-0.58 ; P=0.004)$ and prognostic index (HR 2.71; $95 \% \mathrm{Cl} 1.37-5.35 ; P=0.004)$ were significant factors. After matching, AbiRT continued to be associated with improved OS (median OS not reached vs. 44.0 months, $P=0.009$ ). Subgroup analysis revealed that patients aged $\leq 65$ years (HR 0.09; $95 \% \mathrm{Cl} 0.01-0.65 ; P=0.018)$, PSA $\leq 20 \mathrm{ng} / \mathrm{mL}$ (HR 0.29; 95\% Cl 0.09-0.99; $P=0.048)$, chemotherapy-naïve upon abiraterone treatment (HR 0.20; $95 \% \mathrm{Cl} 0.06-0.66 ; P=0.008)$ and in intermediate prognosis groups by COU-AA-301 prognostic index ( $\mathrm{HR} 0.13 ; 95 \% \mathrm{Cl} 0.03-0.57 ; P=0.007$ ) had improved OS with AbiRT.
\end{abstract}

Conclusions: $C R T$ before resistance to abiraterone may improve survival in selected $\mathrm{mCRPC}$ patients: age $\leq 65$ years old, chemotherapy-naïve, with a relatively low PSA level at the diagnosis of MCRPC and intermediate prognosis.

Keywords: Metastatic castration-resistant prostate cancer, Cytoreduction, Radiotherapy, Abiraterone

*Correspondence: liyongh@sysucc.org.cn; helir@sysucc.org.cn

${ }^{\dagger}$ Yang Liu and Wen Long contributed equally to the work

1 Department of Radiation Oncology, Sun Yat-Sen University Cancer Center, State Key Laboratory of Oncology in South China, Collaborative Innovation Center for Cancer Medicine, 651 Dongfeng Road East, Guangzhou 510060, People's Republic of China

${ }^{3}$ Department of Urology, Sun Yat-Sen University Cancer Center, State Key Laboratory of Oncology in South China, Collaborative Innovation Center for Cancer Medicine, 651 Dongfeng Road East, Guangzhou 510060, People's Republic of China

Full list of author information is available at the end of the article

\section{Background}

Prostate cancer is the second most commonly diagnosed cancer in men worldwide [1]. The incidence of metastatic prostate cancer has been increasing, and the number of new cases of metastatic prostate cancer is estimated to increase by $42 \%$ over the next decade [2]. Nearly all metastatic prostate cancer will progress into an aggressive state known as metastatic castration-resistant prostate cancer (mCRPC). Without effective treatment, the median OS

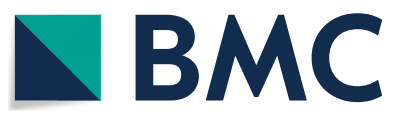

(c) The Author(s) 2021. Open Access This article is licensed under a Creative Commons Attribution 4.0 International License, which permits use, sharing, adaptation, distribution and reproduction in any medium or format, as long as you give appropriate credit to the original author(s) and the source, provide a link to the Creative Commons licence, and indicate if changes were made. The images or other third party material in this article are included in the article's Creative Commons licence, unless indicated otherwise in a credit line to the material. If material is not included in the article's Creative Commons licence and your intended use is not permitted by statutory regulation or exceeds the permitted use, you will need to obtain permission directly from the copyright holder. To view a copy of this licence, visit http://creativecommons.org/licenses/by/4.0/. The Creative Commons Public Domain Dedication waiver (http://creativeco mmons.org/publicdomain/zero/1.0/) applies to the data made available in this article, unless otherwise stated in a credit line to the data. 
of these patients is only 9-30 months [3]. In recent years, major advances in therapeutic agents has significantly improved the survival of $\mathrm{mCRPC}$ patients. Abiraterone is one of the standard of care for mCRPC. Abiraterone plus prednisone has shown remarkable efficacy and safety in chemotherapy-naïve and chemotherapy-treated mCRPC patients $[4,5]$. However, heterogenous responses to abiraterone exist due to the polyclonal nature of metastatic sites, and acquired resistance to abiraterone eventually develop after 6-14 months $[4,5]$. Thus, increasing studies are investigating the potential benefit of adding local therapy to systemic therapy in metastatic prostate cancer.

Current cytoreductive treatment strategies for metastatic prostate cancer includes prostate-directed therapy and metastasis-directed therapy. The STAMPEDE trial demonstrates that prostate-directed radiotherapy could prolong survival in metastatic hormone-sensitive prostate cancer (mHSPC) with low metastatic burden [6], and the HORRAD trial also suggests prolonged PSA progression in mHSPC with less than 5 metastases [7]. Beyond local cytoreduction of primary sites, reducing the metastatic burden through local therapy may also bring survival benefit, as observed in ovarian, kidney and some gastrointestinal cancers [8-10]. In prostate cancer, metastasis-directed radiotehrapy is increasingly endorsed in patients with limited metastatic lesions early in their chain of progression. Stereotactic body radiotherapy (SBRT) to all metastatic sites is likely to delay disease progression and prolong systemic in oligometastatic mHSPC, as supported by the results of some phase II trials such as STOMP, ORIOLE and POPSTAR [11-13].

Given the promising results of cytoreductive radiotherapy in mHSPC, we hypothesized that cytoreductive radiotherapy might as well have a role in the event of mCRPC, a more terminal state. In this retrospective study, we sought to investigate the potential benefit of cytoreductive radiotherapy (cRT) in mCRPC patients treated with abiraterone.

\section{Methods}

\section{Patient selection and baseline evaluation}

This study was approved by the institutional review board. We retrospectively reviewed 320 prostate cancer patients treated with abiraterone plus prednisone between February 2014 and February 2019 in our institution. Inclusion criteria were $\mathrm{mCRPC}$ patients receiving abiraterone with or without radiotherapy. Patients were excluded if they were HSPC or nonmetastatic at the time of abiraterone treatment. Patients lost to follow-up less than 3 months after abiraterone treatment, who discontinued abiraterone treatment for financial burden, or who lacked data for risk stratification were also excluded.
Finally, a total of 149 patients were included in the analyses (Fig. 1).

Oligometastasis was defined as $\leq 5$ metastatic lesions to lymph nodes and/or bones without visceral metastasis [14]. Risk stratification was determined by a prognostic index developed from the COU-AA-301 study [15], which has been validated in both chemotherapy-naive and chemotherapy-treated mCRPC patients [16, 17]. This model comprises six risk factors: lactate dehydrogenase > upper limit of normal (ULN); Eastern Cooperative Oncology Group performance status of 2; liver metastases; albumin $\leq 4 \mathrm{~g} / \mathrm{dL}$; alkaline phosphatase $>\mathrm{ULN}$; time from start of initial androgen-deprivation therapy (ADT) to treatment initiation is $\leq 36$ months. Patients were categorized into good ( $0-1$ risk factor), intermediate (2-3 risk factors) and poor (4-6 risk factors) prognostic groups.

\section{Treatment}

cRT was prescribed for patients in whom radiotherapy covered the lesions that accounted for $>50 \%$ of the total tumor burden [18]. Patients who received cRT could be oligometastatic, or polymetastatic with most of the lesions locating in one region (e.g. pelvis). Radiotherapy to the prostate could be for symptom relief or tumor cytoreduction. Patients treated with cRT before abiraterone failure were placed in the AbiRT group. The comparison group was patients who did not receive cRT before abiraterone failure (non-AbiRT group), including patients receiving $\mathrm{cRT}$ after abiraterone failure (cRT + non-Abi) and no cytoreductive RT (non-cRT). All patients had ADT together with $1000 \mathrm{mg}$ of abiraterone once-daily and $5 \mathrm{mg}$ of prednisone twice-daily. Abiraterone was not withheld or its dose was not reduced during radiotherapy.

Primary sites were treated with intensity-modulated radiotherapy, and all metastatic sites were treated with

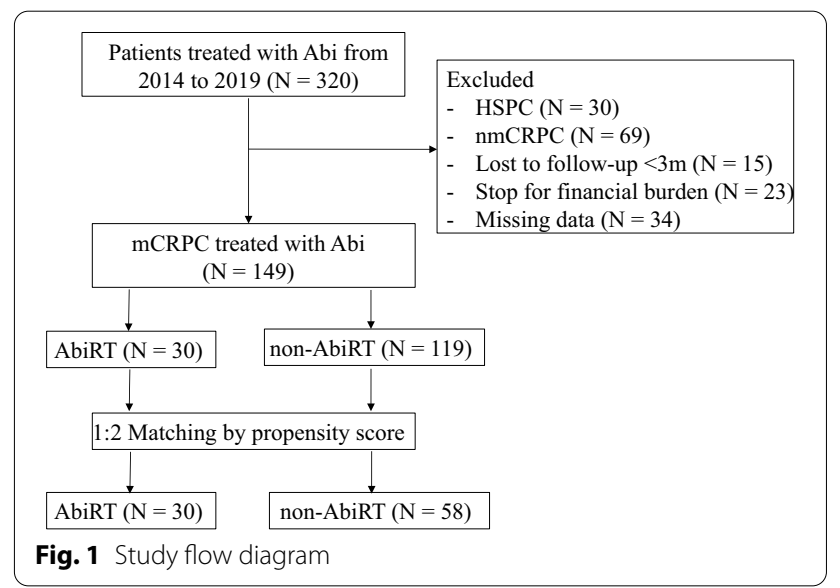


SBRT. Patients underwent simulation with contrastenhanced CT (slice thickness $=3 \mathrm{~mm}$ ) with site-specific immobilization. Planning CT images were fused with magnetic resonance images of the skeletal segment interested. Contouring was in accordance with the corresponding recommendations set by the Radiation Therapy Oncology Group (RTOG). For the prostate, the clinical target volume (CTV) included the prostate gland with or without seminal vesicles, and the planning target volume (PTV) was yielded by expansion by $5 \mathrm{~mm}$ ( $3 \mathrm{~mm}$ posteriorly). Regional lymph nodes were not contoured unless radiographically positive. Distant metastases were treated with SBRT. The CTV equals the gross tumor volume. The PTV was defined as the CTV plus a margin of $\leq 5 \mathrm{~mm}$.

The prescription dose for the prostate gland and pelvic lymph nodes was $60-67.5$ Gy and $45-60$ Gy in 25 fractions, respectively. The dosage regimen for metastatic lesions was $18-35$ Gy in 1-5 fractions. Dose constraints for normal tissue were in accordance with RTOG guidelines [19]. Treatment was delivered by a linear accelerator using 6-8 MV photons. Image guided radiation therapy using cone-beam CT was performed before each treatment fraction.

\section{Outcomes}

For patients treated with radiotherapy, the PSA tests were carried out 1 month after radiotherapy, and every 3 months thereafter. For patients treated with abiraterone alone, PSA was generally tested every 3 months. Radiological evaluation was ordered at the discretion of physicians. OS was defined as the time from the diagnosis of mCRPC until last follow-up or death from any cause. Progression-free survival (PFS) was measured from the start of radiotherapy until PSA or radiographic progression or death. Biochemical and radiographic progression was assessed according to the Prostate Cancer Clinical Trials Working Group 2 (PCWG2). PSA response was defined as a decline in PSA levels of $>50 \%$ from baseline, measured twice 4 weeks apart.

\section{Statistical analysis}

To address the imbalance of potential confounders, we used propensity score matching to compare the OS between the AbiRT and non-AbiRT group. The propensity score was estimated as the probability of receiving AbiRT from a logistic regression model. Variables that were prognostic for OS were explored. The propensityscore model included age, Gleason score, PSA level at mCRPC, prognostic group, synchronous metastasis, oligometastasis, chemotherapy-naïve upon abiraterone treatment. One-to-two matching without replacement was implemented using nearest-neighbor matching. The caliper width was 0.2 times the standard deviation of the logit of the propensity score.

Categorical data were compared using the chi-squared test. OS and PFS were estimated using the Kaplan-Meier method and compared using the log-rank test. The Cox proportional hazard model was used for univariate and multivariate analyses. Variables that were significant in the univariate analysis were included in the multivariate analysis. A $P$ value of less than 0.05 was considered significant. All tests were two-sided. Descriptive analysis and survival analyses were carried out by SPSS v23 (IBM, Armonk, NY, USA). Matching of propensity scores was done by Python (www.Python.org).

\section{Results}

The baseline characteristics of the entire cohort are summarized in Table 1. The median PSA level at the time of $\mathrm{mCRPC}$ diagnosis was $16.8 \mathrm{ng} / \mathrm{mL}$ (range $0.2-3411.0 \mathrm{ng} /$ $\mathrm{mL})$. Seventy-nine patients (53.0\%) had a Gleason score of 9 or 10 at diagnosis of prostate cancer. Synchronous metastasis was present in 127 patients (85.2\%). Fiftyeight patients (38.9\%) had oligometastasis at the time of mCRPC diagnosis. The number of patients allocated to good, intermediate and poor prognostic groups was $65(43.6 \%), 75(50.3 \%)$ and $9(6.0 \%)$, respectively. Fifty-four patients received docetaxel $\left(65-75 \mathrm{mg} / \mathrm{m}^{2}\right)$ every 3 weeks, with 26 cases (17.4\%) before abiraterone

\begin{tabular}{lc}
$\begin{array}{l}\text { Table } 1 \text { Baseline characteristics of the entire cohort } \\
\text { (N=149) }\end{array}$ & No. (\%) \\
\hline Characteristics & $68(45-86)$ \\
\hline Age, median (range), years & \\
PSA at mCRPC & $80(53.7)$ \\
$\leq 20 \mathrm{ng} / \mathrm{mL}$ & $69(46.3)$ \\
$>20 \mathrm{ng} / \mathrm{mL}$ & \\
Gleason score ${ }^{\text {a }}$ & \\
$\leq 8$ & $70(47.0)$ \\
9-10 & $79(53.0)$ \\
ECOG & \\
0-1 & $105(70.5)$ \\
$>1$ & $44(29.5)$ \\
Prognostic index & \\
Good & $65(43.6)$ \\
Intermediate & $75(50.3)$ \\
Poor & $9(6.0)$ \\
Synchronous metastasis & $127(85.2)$ \\
Oligometastasis & $58(38.9)$ \\
Chemo-naive & $123(82.6)$ \\
\hline PSA prosta &
\end{tabular}

PSA prostate-specific antigen, $M C R P C$ metastatic castration-resistant prostate cancer, Chemo-naïve chemotherapy-naïve upon abiraterone treatment

a Gleason score at diagnosis of prostate cancer

b The COU-AA-301 prognostic index 
treatment. Forty patients $(26.8 \%)$ underwent cRT, with 12 (30.0\%), 10 (25.0\%) and 18 (45.0\%) patients receiving cRT to prostate, metastatic sites, and both prostate and metastatic sites. Thirty $(75.0 \%)$ patients were irradiated before abiraterone failure, and the remaining 10 patients (25.0\%) received cRT with concurrent secondary hormone therapies after abiraterone failure.

Thirty patients $(20.1 \%)$ were in the AbiRT group, whereas 119 patients (79.9\%) were in the non-AbiRT group. Compared with the non-AbiRT group, patients in the AbiRT group were more likely to have oligometastasis $(P=0.002)$, with a lower PSA level at $\mathrm{mCRPC}$ diagnosis $(P=0.005)$. Other baseline characteristics including age, Gleason score, synchronous metastasis, chemotherapynaïve upon abiraterone treatment and prognostic index were similar (Table 2).

At a median follow-up of 23.5 months, 54 patients (36.2\%) died. Seven patients $(4.7 \%)$ were lost to followup, 3 in the AbiRT group and 4 in the non-AbiRT group. The local control rate following AbiRT was $96.7 \%$. The median OS of the entire cohort was 38.4 months. The median OS of patients undergoing cRT was not reached, compared with 31.4 months in patients who did not have cRT $(P=0.001)$ (Fig. 2). The 2-year OS rates of patients managed by AbiRT, cRT after abiraterone failure, and no cRT was $89.5 \%, 72.0 \%$ and $72.0 \%$, respectively $(P=0.001)$. The median PFS following radiotherapy in the AbiRT group was 12.2 months, and $23(76.6 \%)$ patients had a PSA response after radiotherapy. Chemotherapy was the most frequently chosen treatment (40.0\%) after progression, followed by estramustine (15.0\%). The median OS of the AbiRT group was not reached whereas, in the non-AbiRT group, the median OS was 31.8 months $(P=0.0003)$. The 2-year OS rates of the AbiRT group and non-AbiRT group were $89.5 \%$ and $73.5 \%$, respectively $(P=0.0003)$ (Fig. 3). Upon univariate analysis, AbiRT, oligometastasis, intermediate/poor group according to the prognostic index, PSA $>20 \mathrm{ng} / \mathrm{mL}$ and chemotherapy-naïve upon abiraterone treatment were significant prognostic factors for OS (Table 3). Upon multivariate analysis, the AbiRT group [hazard ratio (HR), 0.17; 95\% confidence interval $(\mathrm{CI}), 0.05-0.58 ; P=0.004$ ] and intermediate/poor grouping for the prognostic index (HR $2.71 ; 95 \%$ CI $1.37-5.35 ; P=0.004$ ) were significant prognostic factors (Table 3).

After propensity score matching with a caliper of $0.21,30$ patients in the AbiRT group were matched to 58 patients in the non-AbiRT group. The difference between the baseline characteristics was not significant after matching (Table 2). The survival advantage of AbiRT remained significant. The median OS was not reached in the AbiRT group, compared with 44.0 months in the non-AbiRT group $(P=0.009)$. The 2-year OS of the AbiRT group and non-AbiRT group was $89.5 \%$ and 79.3\%, respectively (Fig. 3).

The AbiRT group was associated with improved OS in the subgroups of age $\leq 65$ years old, PSA $\leq 20 \mathrm{ng} / \mathrm{mL}$ and chemotherapy-naïve upon abiraterone treatment (Fig. 4).

Table 2 Comparison of baseline characteristics in the unmatched and the matched data

\begin{tabular}{|c|c|c|c|c|c|c|}
\hline \multirow[t]{3}{*}{ Characteristics } & \multicolumn{3}{|l|}{ Unmatched data } & \multicolumn{3}{|l|}{ Matched data } \\
\hline & \multicolumn{3}{|l|}{ No. (\%) } & \multicolumn{3}{|l|}{ No. (\%) } \\
\hline & AbiRT $(N=30)$ & Non-AbiRT $(\mathrm{N}=119)$ & $P$ & AbiRT $(\mathrm{N}=30)$ & Non-AbiRT ( $\mathrm{N}=58)$ & $P$ \\
\hline Age, years & & & 0.224 & & & 0.440 \\
\hline$\leq 65$ & $15(50.0)$ & $45(37.8)$ & & $15(50.0)$ & $24(41.3)$ & \\
\hline$>65$ & $15(50.0)$ & $74(62.2)$ & & $15(50.0)$ & $34(58.6)$ & \\
\hline PSA at mCRPC & & & 0.005 & & & 0.667 \\
\hline$\leq 20 \mathrm{ng} / \mathrm{mL}$ & $23(76.6)$ & $57(47.9)$ & & $23(76.6)$ & $42(72.4)$ & \\
\hline$>20 \mathrm{ng} / \mathrm{mL}$ & $7(23.3)$ & $62(52.1)$ & & $7(23.3)$ & $16(27.6)$ & \\
\hline Gleason score & & & 0.435 & & & 0.886 \\
\hline$\leq 8$ & $16(53.3)$ & $54(45.4)$ & & $16(53.3)$ & $30(51.7)$ & \\
\hline $9-10$ & $14(46.6)$ & $65(54.6)$ & & $14(46.6)$ & $28(48.3)$ & \\
\hline Prognostic index & & & 0.107 & & & 0.227 \\
\hline Good & $17(56.6)$ & $48(40.3)$ & & $17(56.6)$ & $25(43.1)$ & \\
\hline Intermediate/poor & $13(43.3)$ & $71(59.7)$ & & $13(43.3)$ & $33(56.9)$ & \\
\hline Oligometastasis & $19(63.3)$ & $39(32.8)$ & 0.002 & $19(63.3)$ & $36(62.1)$ & 0.908 \\
\hline Synchronous metastasis & $24(80.0)$ & $103(86.6)$ & 0.538 & $24(80.0)$ & $48(82.8)$ & 0.750 \\
\hline Chemo-naïve & $28(93.3)$ & $95(79.8)$ & 0.082 & $28(93.3)$ & $53(91.4)$ & 1.000 \\
\hline
\end{tabular}

PSA prostate-specific antigen, $m C R P C$ metastatic castration-resistant prostate cancer, Chemo-naïve chemotherapy-naïve upon abiraterone treatment 

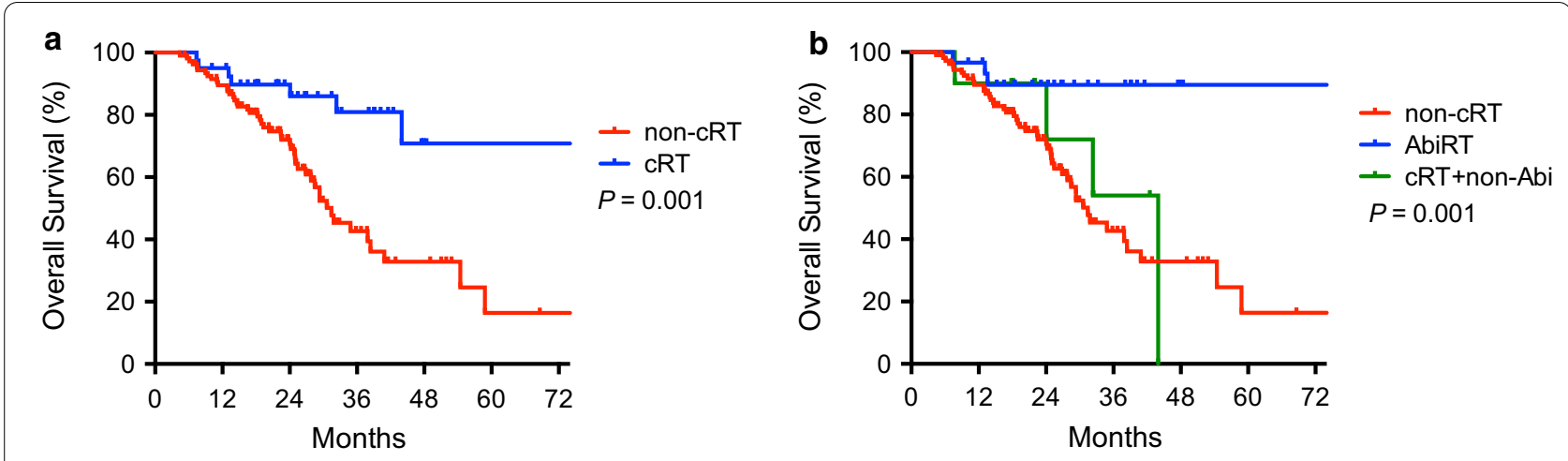

$\begin{array}{llllllllllllllll}\text { non-CRT } & 109 & 94 & 48 & 16 & 9 & 3 & 2 & \text { non-CRT } & 109 & 94 & 48 & 16 & 9 & 3 & 2 \\ \text { cRT } & 40 & 38 & 25 & 15 & 6 & 5 & 5 & \text { AbiRT } & 30 & 29 & 20 & 13 & 6 & 5 & 5 \\ & & & & & & & & \text { cRT+non-AbiRT } & 10 & 10 & 6 & 3 & 0 & 0 & 0\end{array}$

Fig. 2 a Overall survival for patients with $m C R P C$ treated with $(N=40)$ and without $(N=109)$ cytoreductive radiotherapy. b Overall survival of patients treated with cytoreductive RT before abiraterone failure (AbiRT, $N=30$ ), after abiraterone failure together with other secondary hormone therapies (cRT + non-Abi, $N=10$ ) and no cytoreductive RT (non-cRT, N=109)
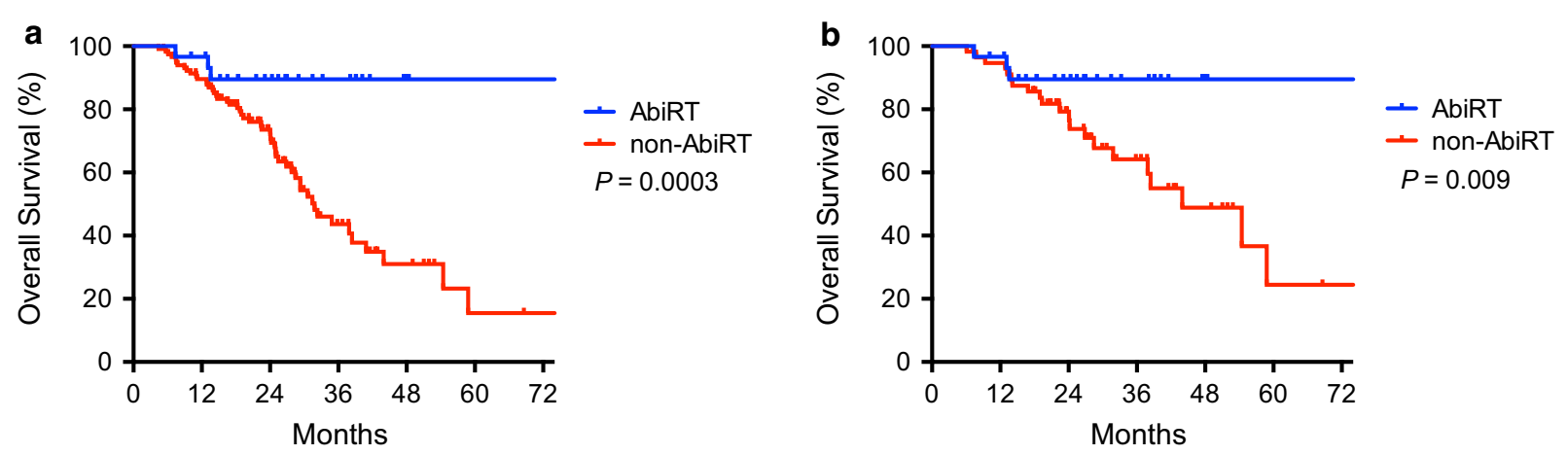

$\begin{array}{lrrrrrrr}\text { AbiRT } & 30 & 29 & 20 & 13 & 6 & 5 & 5\end{array}$

$\begin{array}{llllllll}\text { AbiRT } & 30 & 29 & 20 & 13 & 6 & 5 & 5 \\ \text { non-AbiRT } & 58 & 54 & 30 & 17 & 9 & 3 & 2\end{array}$

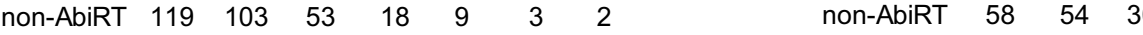

Fig. 3 Overall survival for mCRPC patients treated with (AbiRT) and without (non-AbiRT) cytoreductive RT before abiraterone failure before (a) and after (b) propensity score matching

Table 3 Univariate and multivariable analyses of factors predictive of overall survival

\begin{tabular}{|c|c|c|c|c|}
\hline \multirow[t]{2}{*}{ Variables } & \multicolumn{2}{|c|}{ Univariate analysis } & \multicolumn{2}{|c|}{ Multivariate analysis } \\
\hline & $\mathrm{HR}(95 \% \mathrm{Cl})$ & $P$ & $\mathrm{HR}(95 \% \mathrm{Cl})$ & $P$ \\
\hline \multicolumn{5}{|l|}{ AbiRT } \\
\hline Yes versus no & $0.15(0.05,0.48)$ & 0.001 & $0.17(0.05,0.58)$ & 0.004 \\
\hline \multicolumn{5}{|l|}{ Oligometastasis } \\
\hline Yes versus no & $0.52(0.30,0.93)$ & 0.028 & $0.75(0.39,1.44)$ & 0.387 \\
\hline \multicolumn{5}{|l|}{$\mathrm{PSA}>20 \mathrm{ng} / \mathrm{mL}$} \\
\hline Yes versus no & $2.16(1.23,3.79)$ & 0.007 & $1.66(0.93,2.96)$ & 0.089 \\
\hline \multicolumn{5}{|l|}{ Prognostic index } \\
\hline Interm/poor versus favorable & $3.11(1.64,5.92)$ & 0.001 & $2.71(1.37,5.35)$ & 0.004 \\
\hline \multicolumn{5}{|l|}{ Chemo-naïve at Abi } \\
\hline Yes versus no & $0.45(0.25,0.81)$ & 0.008 & $0.81(0.41,1.61)$ & 0.548 \\
\hline
\end{tabular}

PSA prostate-specific antigen, Interm intermediate, Chemo-naïve chemotherapy-naïve upon abiraterone treatment, $H R$ hazard ratio, $\mathrm{Cl}$ confidential interval 


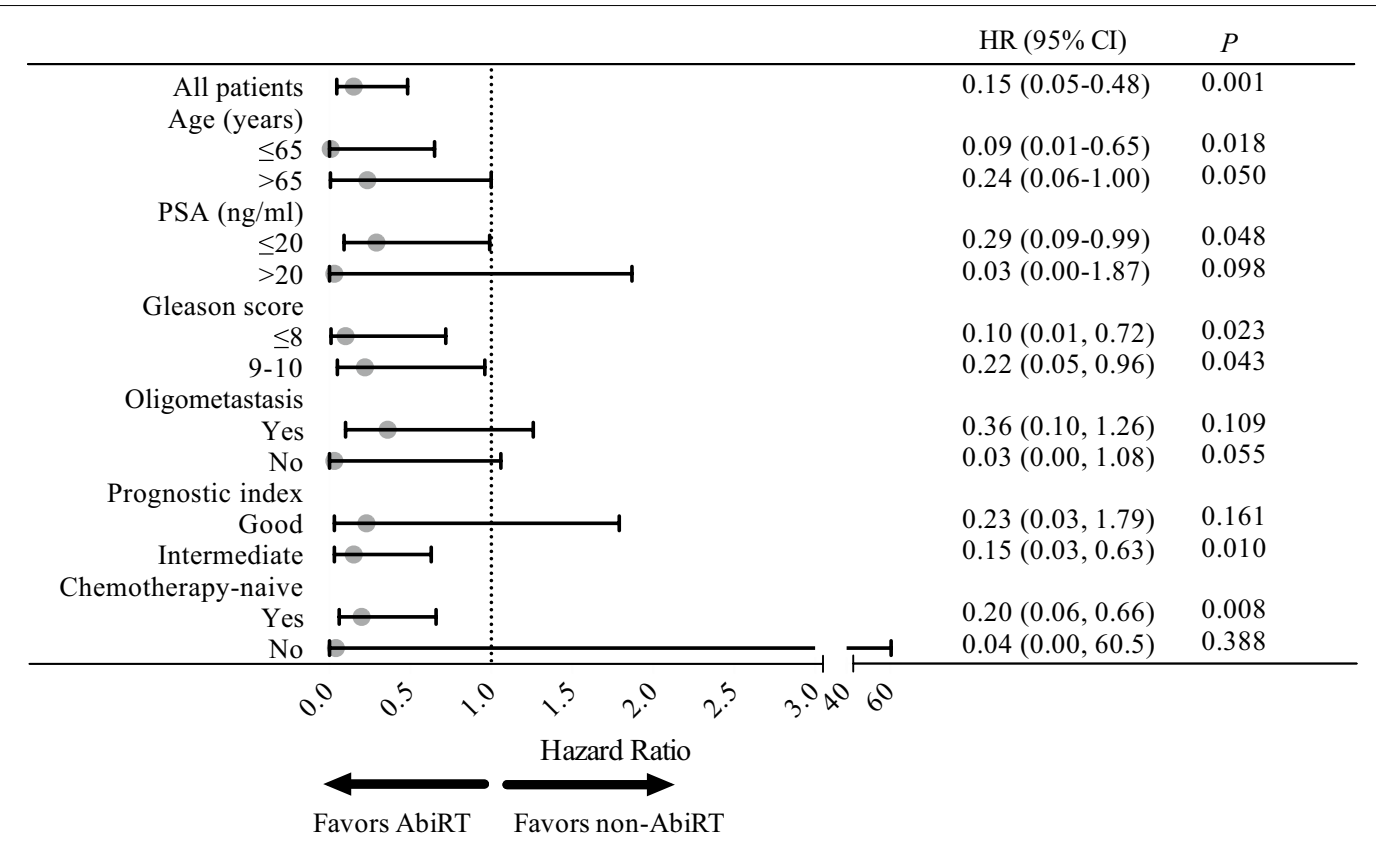

Fig. 4 Forest plot of the association between cytoreductive radiotherapy before abiraterone failure and overall survival by subgroup. HR hazard ratio, 95\% Cl 95\% confidence interval

The benefit of AbiRT was not evaluated in patients with poor prognosis according to the prognostic index given that there were only nine patients in this subgroup. In the subgroup with an intermediate prognosis according to the prognostic index, application of AbiRT was associated with a reduction of death of $85 \%$ (HR 0.15 ; 95\% CI $0.03-0.63 ; P=0.010$ ); this advantage was not observed in patients with a good prognosis (HR 0.23; 95\% CI 0.03$1.79 ; P=0.161)$.

Radiotherapy was well tolerated, with no grade 3 or higher toxicities reported. Acute side effects included gastrointestinal (GI) toxicity (9 patients), genitourinary (GU) toxicity (11 patients), thrombocytopenia (1 patient), neutropenia (1 patient) and hypokalemia (1 patient). Late GI and GU toxicity were observed in 7 and 6 patients, respectively. Two patients developed vertebral compression fractures, and neither of them were symptomatic.

\section{Discussion}

Evolving novel hormonal agents have improved the systemic control and prolonged survival of MCRPC patients, and increasing focus is being placed on the potential benefits of cytoreductive local therapy [20]. This study provides valuable insights regarding the value of cytoreductive radiotherapy in $\mathrm{mCRPC}$. In this comparison of survival outcomes between the two groups (AbiRT vs. non-AbiRT), cRT before abiraterone failure was associated with a remarkable improvement in OS, and adoption of cRT required careful consideration when systemic control could no longer be maintained by abiraterone therapy. Patients aged $\leq 65$ years with PSA $\leq 20 \mathrm{ng} / \mathrm{mL}$, who were chemotherapy-naïve and belonged to the intermediate prognostic group may be potential candidates for cytoreductive therapies.

Addition of radiotherapy to androgen receptor axistargeted therapy (ARAT) may provide additional advantages [21]. Androgen-receptor signaling can promote radioresistance by accelerating repair of the DNA damage induced by ionizing radiation [22], and new-generation ARAT can result in downregulation of expression of the DNA repair genes, thereby potentiating the effect of ionizing radiation [23]. In clinical studies, a delay of disease progression has been observed after delivering radiotherapy to $\mathrm{mCRPC}$ patients treated with abiraterone [24-26]. Similarly, our study showed that the survival benefit was most pronounced if cRT was combined with abiraterone. Ongoing clinical trials (NCT03449719 and NCT03556904) will help to decide whether combining radiotherapy and abiraterone could provide additional advantage in mCRPC.

cRT can discontinue direct seeding of new metastases as well as stopping supportive interactions between primary and metastatic sites $[27,28]$. cRT can also eliminate resistant clones and release a wider range of tumor antigens [29]. Emerging clinical evidence suggests that cRT can significantly prolong PFS and even OS in mHSPC [6, 11-13]. In contrast, cRT for mCRPC seems less attractive because the value of local therapy at such a late stage 
is questionable. Several retrospective studies show that radiotherapy to oligoprogressive sites could delay disease progression in mCRPC [24, 26, 30]. Yildirim et al. observed no significant improvement of OS was found following prostate-directed radiotherapy in MCRPC (24.1 vs. 21.4 months; $P=0.08$ ), while Fujita et al. reported significant improvement of OS (66 vs. 22 months; $P=0.001$ ), with 2 -year OS around $85 \%$ in the prostatedirected radiotherapy group [31]. Our study echoed the finding of Fujita et al., with 2-year OS of $89.5 \%$ in the AbiRT group. As half of the patients in the study by Yildirim et al. were post-docetaxel, and the patients in our study and the study of Fujita et al. were predominantly chemotherapy-naïve, it could be speculated that patients are more likely to have survival benefit when cytoreductive local therapy is adopted at an early stage of mCRPC [14]. These results imply that the power of cytoreductive local therapy is restricted at a terminal stage of disease, especially if multiple lines of treatment have failed. Another point to consider is the extent of radiotherapy. The extent of local therapy could affect survival in solid tumors [32, 33]. Previous studies in mCRPC focused exclusively on prostate-directed therapy or oligoprogressive metastases-directed therapy alone. Our patients received greater extent of cytoreduction by radiotherapy when abiraterone was effective, which might account for the encouraging result.

In subgroup analyses, the survival benefit from AbiRT was observed in patients in the intermediate prognostic group instead of in those in the good prognostic group. These data suggested that abiraterone treatment alone could elicit satisfactory control for some low-risk patients, whereas intensive therapy (e.g., AbiRT) was worth trying for intermediate-risk patients because abiraterone treatment alone might be not sufficient for these patients. Interestingly, oligometastasis could not be used to identify potential candidates for local radiotherapy in our study. Current definition of oligometastasis only offers an assessment of tumor burden in a snapshot, but the underlying clinical pathways that lead to an oligomeatstatic state is undefined. The European Society for Radiotherapy and Oncology and European Organisation for Research and Treatment of Cancer has classified the oligometastates into 9 distinct situations [34]. Oligometastasis can be induced by multiple lines of systemic therapies in $\mathrm{mCRPC}$, and patients who are heavily pretreated are not in their early chain of progression despite having limited metastases. These data suggest that oligometastasis, a generally accepted indication for local cytoreductive therapy in newly diagnosed $\mathrm{mHSPC}$, may not be applicable in mCRPC. Thus, the decision regarding local intervention requires combined interpretation of the patient's general condition, disease state and the profile of systemic treatment [14]. Patients who are not heavilypretreated, and those who are relatively young with good treatment tolerance as well as a low level of PSA, may benefit from aggressive local therapy in $\mathrm{mCRPC}$.

Our study has several limitations. First, it is a retrospective study. However, given the lack of evidence on the role of cytoreductive radiotherapy in the general situation other than oligometastasis and oligoprogression, our study provides valuable information for current practice. Second, excluding patients with missing data might have led to selection bias (though there is no evidence that these patients were more or less prone to be omitted based on the scarce information in the medical records). Third, our patients represent a heterogenous cohort of mCRPC patients who received different treatment at different time points.

\section{Conclusions}

The present study evaluated the survival outcomes of cytoreductive radiotherapy in mCRPC patients treated with abiraterone. The findings from our study support the use of cytoreductive radiotherapy before the resistance to abiraterone in selected mCRPC patients, preferably in age $\leq 65$ years old, chemotherapy-naïve, with $\mathrm{PSA} \leq 20 \mathrm{ng} / \mathrm{mL}$ at the time of $\mathrm{mCRPC}$ and intermediate prognosis.

\section{Abbreviations}

OS: Overall survival; mCRPC: Metastatic castration-resistant prostate cancer; mHSPC: Metastatic hormone-sensitive prostate cancer; ADT: Androgendeprivation therapy; SBRT: Stereotactic body radiotherapy; CRT: Cytoreductive radiotherapy; ULN: Upper limit of normal; AbiRT: Cytoreductive radiotherapy before abiraterone failure; non-AbiRT: No cytoreductive radiotherapy before abiraterone failure; RTOG: Radiation Therapy Oncology Group; CTV: Clinical target volume; PTV: Planning target volume; PFS: Progression-free survival; PCWG2: Prostate Cancer Clinical Trials Working Group 2; GI: Gastrointestinal; GU: Genitourinary.

\section{Acknowledgements \\ Not applicable.}

\section{Authors' contributions}

LY and LW participated in study design, statistical analysis and manuscript drafting. DP collected the clinical data. ZZT, MLX, HSJ, LBJ, CWF, WJH and ZFJ contributed to the operation work during treatment. LYH and HLR designed the study, reviewed and revised the manuscript. All authors read and approved the final manuscript.

\section{Funding}

This study was funded by General Program of National Natural Science Foundation of China (81772483).

\section{Availability of data and materials}

The datasets used and/or analyzed during the current study are available from the corresponding author on reasonable request.

\section{Ethics approval and consent to participate}

This project was approved by the Ethical Committee of Sun Yat-Sen University Cancer Center and informed consent was waived by the committee. 


\section{Consent for publication}

Not applicable.

\section{Competing interests}

The authors declare that they have no competing interests.

\begin{abstract}
Author details
1 Department of Radiation Oncology, Sun Yat-Sen University Cancer Center, State Key Laboratory of Oncology in South China, Collaborative Innovation Center for Cancer Medicine, 651 Dongfeng Road East, Guangzhou 510060, People's Republic of China. ${ }^{2}$ Department of Nuclear Medicine, Sun Yat-Sen University Cancer Center, State Key Laboratory of Oncology in South China, Collaborative Innovation Center for Cancer Medicine, Guanghzou, People's Republic of China. ${ }^{3}$ Department of Urology, Sun Yat-Sen University Cancer Center, State Key Laboratory of Oncology in South China, Collaborative Innovation Center for Cancer Medicine, 651 Dongfeng Road East, Guangzhou 510060, People's Republic of China.
\end{abstract}

Received: 2 July 2020 Accepted: 17 December 2020

Published online: 06 January 2021

\section{References}

1. Bray F, Ferlay J, Soerjomataram I, Siegel RL, Torre LA, Jemal A. Global cancer statistics 2018: GLOBOCAN estimates of incidence and mortality worldwide for 36 cancers in 185 countries. CA Cancer J Clin. 2018;68(6):394-424

2. Kelly SP, Anderson WF, Rosenberg PS, Cook MB. Past, current, and future incidence rates and burden of metastatic prostate cancer in the United States. Eur Urol Focus. 2018;4:121-7.

3. Kirby M, Hirst C, Crawford ED. Characterising the castration-resistant prostate cancer population: a systematic review. Int J Clin Pract. 2011;65(11):1180-92.

4. Ryan CJ, Smith MR, Fizazi K, Saad F, Mulders PF, Sternberg CN, et al. Abiraterone acetate plus prednisone versus placebo plus prednisone in chemotherapy-naive men with metastatic castration-resistant prostate cancer (COU-AA-302): final overall survival analysis of a randomised, double-blind, placebo-controlled phase 3 study. Lancet Oncol. 2015;16(2):152-60.

5. Fizazi K, Scher HI, Molina A, Logothetis CJ, Chi KN, Jones RJ, et al. Abiraterone acetate for treatment of metastatic castration-resistant prostate cancer: final overall survival analysis of the COU-AA-301 randomised, double-blind, placebo-controlled phase 3 study. Lancet Oncol. 2012;13(10):983-92.

6. Parker CC, James ND, Brawley CD, Clarke NW, Hoyle AP, Ali A, et al. Radiotherapy to the primary tumour for newly diagnosed, metastatic prostate cancer (STAMPEDE): a randomised controlled phase 3 trial. Lancet 2018;392(10162):2353-66

7. Boeve LMS, Hulshof M, Vis AN, Zwinderman AH, Twisk JWR, Witjes WPJ, et al. Effect on survival of androgen deprivation therapy alone compared to androgen deprivation therapy combined with concurrent radiation therapy to the prostate in patients with primary bone metastatic prostate cancer in a prospective randomised clinical trial: data from the HORRAD Trial. Eur Urol. 2019;75(3):410-8.

8. Dabestani S, Marconi L, Hofmann F, Stewart F, Lam TB, Canfield SE, et al. Local treatments for metastases of renal cell carcinoma: a systematic review. Lancet Oncol. 2014;15(12):e549-61.

9. Bristow RE, Tomacruz RS, Armstrong DK, Trimble EL, Montz FJ. Survival effect of maximal cytoreductive surgery for advanced ovarian carcinoma during the platinum era: a meta-analysis. J Clin Oncol. 2002;20(5):1248-59.

10. Glehen O, Mohamed F, Gilly FN. Peritoneal carcinomatosis from digestive tract cancer: new management by cytoreductive surgery and intraperitoneal chemohyperthermia. Lancet Oncol. 2004;5(4):219-28.

11. Ost P, Reynders D, Decaestecker K, Fonteyne V, Lumen N, De Bruycker A et al. Surveillance or metastasis-directed therapy for oligometastatic prostate cancer recurrence: a prospective, randomized, multicenter phase II trial. J Clin Oncol. 2018;36(5):446-53.

12. Radwan N, Phillips R, Ross A, Rowe SP, Gorin MA, Antonarakis ES, et al. A phase II randomized trial of Observation versus stereotactic ablative
Radiatlon for OLigometastatic prostate CancEr (ORIOLE). BMC Cancer. 2017;17(1):453.

13. Siva S, Bressel M, Murphy DG, Shaw M, Chander S, Violet J, et al. Stereotactic abative body radiotherapy (SABR) for oligometastatic prostate cancer: a prospective clinical trial. Eur Urol. 2018;74(4):455-62.

14. Wei XX, Ko EC, Ryan CJ. Treatment strategies in low-volume metastatic castration-resistant prostate cancer. Curr Opin Urol. 2017;27(6):596-603.

15. Chi KN, Kheoh T, Ryan CJ, Molina A, Bellmunt J, Vogelzang NJ, et al. A prognostic index model for predicting overall survival in patients with metastatic castration-resistant prostate cancer treated with abiraterone acetate after docetaxel. Ann Oncol. 2016;27(3):454-60.

16. Khalaf DJ, Avilés CM, Azad AA, Sunderland K, Todenhöfer T, Eigl BJ, et al. A prognostic model for stratifying clinical outcomes in chemotherapynaive metastatic castration-resistant prostate cancer patients treated with abiraterone acetate. Can Urol Assoc J. 2018;12(2):E47-e52.

17. Azad A, Lester R, Leibowitz-Amit R, Joshua AM, Heng DYC, Eigl BJ, et al. Population-based analysis of a novel prognostic model for metastatic castration-resistant prostate cancer (mCRPC) patients (pts) treated with abiraterone acetate (AA). J Clin Oncol. 2014;32(4_suppl):29.

18. He L, Liu Y, Han H, Liu Z, Huang S, Cao W, et al. Survival outcomes after adding stereotactic body radiotherapy to metastatic renal cell carcinoma patients treated with tyrosine kinase inhibitors. Am J Clin Oncol. 2020;43(1):58-63.

19. Lee WR, Dignam JJ, Amin MB, Bruner DW, Low D, Swanson GP, et al. Randomized phase III noninferiority study comparing two radiotherapy fractionation schedules in patients with low-risk prostate cancer. J Clin Oncol. 2016;34(20):2325-32.

20. Connor MJ, Shah TT, Horan G, Bevan CL, Winkler M, Ahmed HU. Cytoreductive treatment strategies for de novo metastatic prostate cancer. Nat Rev Clin Oncol. 2019;17:168-82.

21. Livi L, Detti B, Francolini G, Terziani F, Triggiani L, D'Angelillo RM, et al. Combining abiraterone and radiotherapy in metastatic castrationresistant prostate cancer: a review of current evidence. Tumori. 2019;105(4):277-81

22. Spratt DE, Evans MJ, Davis BJ, Doran MG, Lee MX, Shah N, et al. Androgen receptor upregulation mediates radioresistance after ionizing radiation. Cancer Res. 2015;75(22):4688-96.

23. Polkinghorn WR, Parker JS, Lee MX, Kass EM, Spratt DE, laquinta PJ, et al. Androgen receptor signaling regulates DNA repair in prostate cancers. Cancer Discov. 2013;3(11):1245-53.

24. Detti B, D'Angelillo RM, Ingrosso G, Olmetto E, Francolini G, Triggiani $L$, et al. Combining abiraterone and radiotherapy in prostate cancer patients who progressed during abiraterone therapy. Anticancer Res. 2017;37(7):3717-22.

25. Yildirim BA, Onal C, Kose F, Oymak E, Sedef AM, Besen AA, et al. Outcome of loco-regional radiotherapy in metastatic castration-resistant prostate cancer patients treated with abiraterone acetate. Strahlenther Onkol. 2019;195(10):872-81.

26. Valeriani M, Marinelli L, Macrini S, Reverberi C, Aschelter AM, De Sanctis $\checkmark$, et al. Radiotherapy in metastatic castration resistant prostate cancer patients with oligo-progression during abiraterone-enzalutamide treatment: a mono-institutional experience. Radiat Oncol. 2019;14(1):205.

27. Giri D, Ozen M, Ittmann M. Interleukin-6 is an autocrine growth factor in human prostate cancer. Am J Pathol. 2001;159(6):2159-65.

28. Sehgal I, Powers S, Huntley B, Powis G, Pittelkow M, Maihle NJ. Neuroten$\sin$ is an autocrine trophic factor stimulated by androgen withdrawal in human prostate cancer. Proc Natl Acad Sci U S A. 1994;91(11):4673-7.

29. Brooks ED, Chang JY. Time to abandon single-site irradiation for inducing abscopal effects. Nat Rev Clin Oncol. 2019;16(2):123-35.

30. Berghen C, Joniau S, Ost P, Poels K, Everaerts W, Decaestecker K, et al. Progression-directed therapy for oligoprogression in castration-refractory prostate cancer. Eur Urol Oncol. 2019;23:S2588-9311(19)30138-5.

31. Fujita N, Hatakeyama S, Momota M, Tobisawa Y, Yoneyama T, Ymamoto $\mathrm{H}$, et al. Safety and feasibility of radiation therapy to the primary tumor in patients with metastatic castration-resistant prostate cancer. Clin Genitourin Cancer. 2020;18(5):e523-30.

32. Barbastefano J, Garcia JA, Elson P, Wood LS, Lane BR, Dreicer R, et al. Association of percentage of tumor burden removed with debulking nephrectomy and progression-free survival in patients with metastatic renal cell carcinoma treated with vascular endothelial growth factortargeted therapy. BJU Int. 2010;106:1266-9. 
33. Spiliotis J, Halkia E, Lianos E, Kalantzi N, Grivas A, Efstathiou E, et al, Cytoreductive surgery and HIPEC in recurrent epithelial ovarian cancer: a prospective randomized phase III study. Ann Surg Oncol. 2015;22:1570-5.

34. Guckenberger M, Lievens Y, Bouma AB, Collette L, Dekker A, deSouza

$\mathrm{NM}$, et al. Characterisation and classification of oligometastatic disease: a European Society for Radiotherapy and Oncology and European Organisation for Research and Treatment of Cancer consensus recommendation. Lancet Oncol. 2020;21(1):e18-28.

\section{Publisher's Note}

Springer Nature remains neutral with regard to jurisdictional claims in published maps and institutional affiliations.
Ready to submit your research? Choose BMC and benefit from:

- fast, convenient online submission

- thorough peer review by experienced researchers in your field

- rapid publication on acceptance

- support for research data, including large and complex data types

- gold Open Access which fosters wider collaboration and increased citations

- maximum visibility for your research: over 100M website views per year

At BMC, research is always in progress.

Learn more biomedcentral.com/submissions 